\title{
ARTEFATOS DE COCÇÃO EM FERRO FUNDIDO: agregação de valor a partir do design e da seleção e aplicação de processos de revestimento cerâmico
}

\author{
MIRANDA, Carlos Alberto Silva de. Dr. \\ Universidade do Estado de Minas Gerais - Escola de Design \\ carlosasmiranda@gmail.com \\ MOTTIN, Artur Caron. M.Sc. \\ Universidade do Estado de Minas Gerais - Escola de Design \\ mottindesign@gmail.com \\ DIAS, Maria Regina Álvares Correa. Dra. \\ Universidade do Estado de Minas Gerais - Escola de Design \\ regina.alvares@gmail.com \\ CÂMARA, Jairo José Drummond. Dr. \\ Universidade do Estado de Minas Gerais - Escola de Design \\ camara.jairo@gmail.com
}

\begin{abstract}
Resumo: As panelas e artefatos de cocção em ferro fundido da cidade de Cláudio, em Minas Gerais, são confeccionados em processo semiartesanal, fazendo-se uso de moldagem manual em processo de areia verde. A difusão da tecnologia de esmaltação, enquanto recurso aplicável em projetos orientados a este setor tecnológico melhoraria a competitividade de tais produtos, inserindo uma nova categoria de panelas no polo produtivo em questão. $O$ objetivo da pesquisa aqui relatada, realizada na Escola de Design da UEMG, foi o estudo do de técnicas do processo de esmaltação para posterior transferência da tecnologia de revestimento em cerâmica de artefatos de cocção em ferro fundido, visando agregação de valor a partir da seleção e especificação de texturas e cores aliadas ao design de produtos.
\end{abstract}

Palavras-chave: Design de Produto, ferro fundido, artefatos de cocção, esmaltação.

Abstract: The cast iron cooking artifacts at Claudio' city, in Minas Gerais, are made of semi-artisanal process, making use of manual molding process in green sand. The diffusion of enameling technology, as applicable in resource-oriented projects in this technology sector, could improve the competitiveness of such products, entering a new category of cookware at 
the productive pole in question. The main objective of the research reported here, held at the Design School of UEMG, is to study the subsequent transfer of enameling technology in cast iron cooking artifacts, which will improve the selection and specification of textures and colors combined with the product design.

Keywords: Product design, cast iron, cooking artifacts, enameling.

\section{INTRODUÇÃO}

Desde os primórdios, o ser humano teve sua sobrevivência na Terra marcada pela busca de alimento e moradia, o que culminou em seu caráter nômade. A utilização de materiais sempre esteve presente, e sua utilização e beneficiamento definiram períodos em sua história (KRIPPENDORFF, 2000).

A Idade do Ferro (1200 a 586 a.C.) foi o período no qual o desenvolvimento de artefatos deste metal foi disseminado, principalmente pela criação de fornos que atingiam altas temperaturas, facilitando a fusão do ferro, bem como a busca por novos materiais que pudessem ser utilizados no militarismo eminente da civilização romana (LUNGBERG, 2007). Seu uso também foi presente desdea época Medieval, desembocando na Revolução Industrial, na Era Moderna (KRIPPENDORFF, 2000).

Deste período aos dias atuais, os metais, em especial o ferro, se tornaram presentes no cotidiano de produtos confeccionados pelo homem, nas mais diversas áreas - da bélica a produtos domésticos, tais como os aparelhos de cocção.

Segundo dados da Secretaria de Estado de Desenvolvimento Econômico de Minas Gerais, o setor de fundição é responsável por 33\% dos produtos fundidos brasileiros e por $18 \%$ das exportações.

O crescimento da indústria automobilística no Brasil, primeiro país a reunir as dez maiores montadoras do mundo, contribuiu decisivamente para fortalecer a indústria de fundição, que hoje destina $56 \%$ de sua produção ao setor. A cidade de Cláudio, situada na região centro-oeste deste Estado, apresenta uma peculiaridade referente a esta setor, por ser o maior pólo da América Latina na produção de fundidos destinados ao uso doméstico, contando com mais de 80 empresas que produzem móveis, adornos e objetos decorativos e utensílios de cocção em ferro fundido cinzento, no antigo processo de fusão em fornos cubilot ${ }^{1}$ e em alumínio fundido, em fornos elétricos ou a óleo.

O sistema de produção é arcaico e de característica semi-artesanal, fazendo-se uso de moldagem manual em processo de areia verde, salvo o caso de uma ou outra empresa que utiliza a moldagem mecanizada, porém com o processo de fusão e vazamento do ferro ainda manuais.

\footnotetext{
${ }^{1}$ Trata-se de um forno cilíndrico no qual os materiais de fusão (geralmente lingotes de ferro gusa) são adicionados emcamadas e estão em contato direto com o combustível (coque), no qual o processo de fusão é auxiliado por um fundente(geralmente seixos), visando a produção do ferro fundido, a partir da redução.
} 
A Figura 1 ilustra o ambiente fabril e sistema produtivo, os quais variam pouco de empresa para empresa, naquela região. Em sua maioria, estes empreendimentos são de pequeno porte, com características de administração familiares e orientadas ao mercado varejista.

Quanto aos produtos fabricados pelas empresas desta região, existe uma consciência e desejo por parte dos empresários, no sentido de encaminharem seus empreendimentos em direção a uma produção de produtos com maior valor agregado e focos de mercado mais definidos, porém não foram observadas, até então, ações eficazes direcionadas a esta finalidade.

A perda de mercado e a não formação de uma identidade percebida por parte das empresas é decorrente do desconhecimento de ferramentas das diversas áreas relacionadas ao desenvolvimento de produtos, marketing, comunicação e imagem corporativa. O desenvolvimento de produtos nestas empresas é feito de forma descoordenada e muitas vezes sem foco ou sem a aplicação de uma metodologia eficiente.
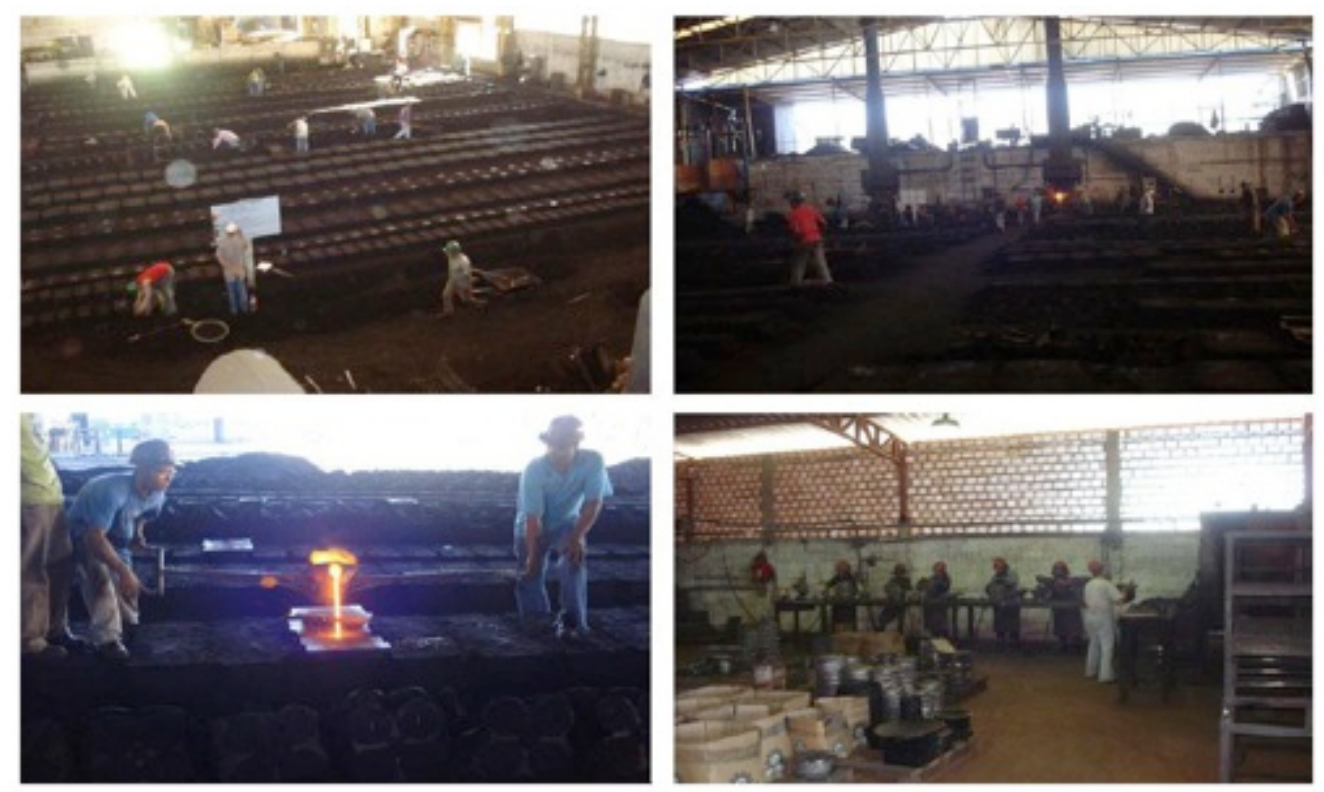

Figura 1 - Processo produtivo de uma empresa de fundição da Região de Claudio/MG caracterizada por manufatura de baixa tecnologia e a produção semi-artesanal.

Fonte: Elaborado pelos autores, com base na pesquisa realizada.

A desconsideração de fatores vitais inerentes a um bom projeto e a comum prática da cópia de produtos feita por estas empresas acaba resultando em um enorme número de produtos equivocados e fora das realidades de mercado e consumo. Isso pode ser comprovado a partir da contraposição entre os produtos importados de alto valor agregado e os produtos relacionados no catálogo destas empresas (Figura 2). Pode-se notar a rusticidade e a robustez inerentes a todos os produtos atualmente fabricados na região. 


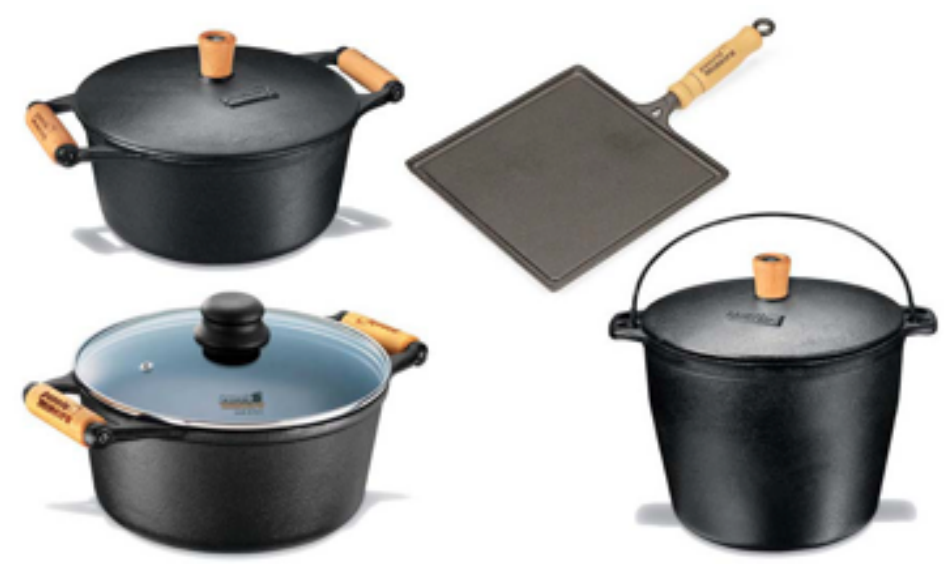

Figura 2 - Exemplos de produtos usualmente fabricados na Região de Claudio/MG.

Fonte: Elaborado pelos autores, com base na pesquisa realizada. Imagens coletadas nos websites dos fabricantes.

A partir da constatação da defasagem tecnológica dos produtos de cocção relatados em relação aos concorrentes e similares importados, identificou-se a necessidade emergente do desenvolvimento tecnológico de um revestimento que proporcionasse a aplicação de cores, além de melhorar a aparência dos produtos. 0 propósito seria de tornar os produtos mais amigáveis e permitir o seu uso nas cozinhas residenciais, haja vista que os produtos tradicionais da região têm seu uso restrito a fazendas e casas de campo, especificamente em fogões à lenha. Nota-se, na Figura 2, que o único revestimento superficial disponível para aqueles produtos é a tinta de coloração negra, à base de material antiaderente, o PTFE (Teflon).

Sabe-se que essa tecnologia é possível em escala industrial, no qual é observada sua aplicação em produtos importados de grande valor agregado (Figura 3) que estão disponíveis em nosso mercado a partir de importação, com alto custo e nicho de mercado estabelecido, como por exemplos os produtos das empresas francesas Staub e Le Creuset. Todavia, nota-se que o mercado começa a oferecer produtos similares com o mesmo revestimento, provenientes da China, o que caracteriza a pertinência de ações de desenvolvimento. Porém, torna-se necessário a averiguação da aplicabilidade desta tecnologia nos produtos, a partir do levantamento tecnológico proposto neste trabalho, além da verificação e possibilidade de adaptação desta tecnologia à realidade das empresas da região.

Nota-se nos produtos da Figura 3, maior valor agregado e a diferenciação proporcionada pelo uso das cores, bem como a melhoria da performance do produto, nos quesitos assepsia, estética e funcionalidade. 


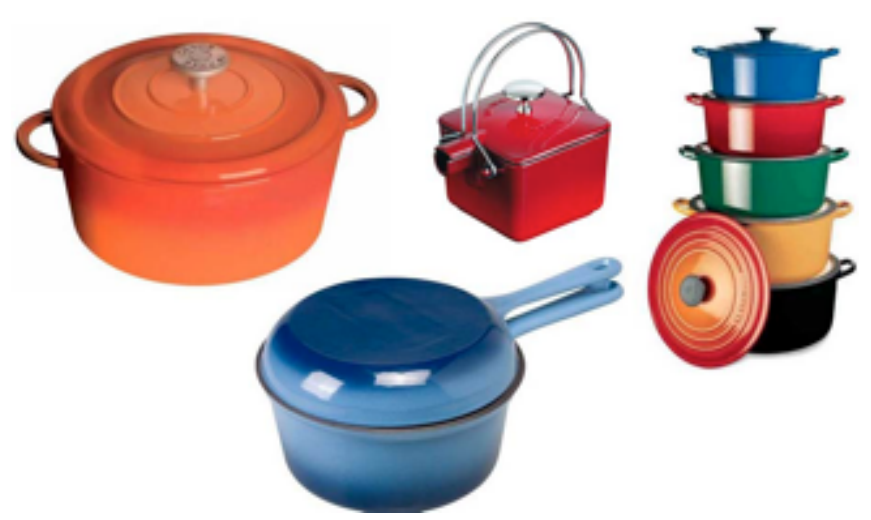

Figura 3 - Exemplos de utensílios de cocção com revestimento cerâmico importados e comercializados no Brasil.

Fonte: Elaborado pelos autores, com base na pesquisa realizada. Imagens coletadas nos websites dos fabricantes.

Conforme MÓL (2005), pouco depois de dominar a técnica de produção de fogo, o homem manipulou a cerâmica e criou o utensílio que é utilizado até hoje por praticamente todas as culturas: a panela. A criação de tal produto permitiu uma grande revolução da alimentação humana, uma vez que proporcionou o consumo de cereais e carnes assados. Ainda conforme o autor, os recipientes de cerâmica da era pré-histórica eram utilizados também para a fabricação de bebidas fermentadas, além de favorecer a proteção de alimentos. Praticamente toda a civilização possui uma maneira particular de promover a coç̧ão dos alimentos, e o desenvolvimento do setor ao longo dos séculos foi favorecido, e muito, pelo desenvolvimento de novas tecnologias e a adoção de novos materiais em sua fabricação. Todavia, ainda hoje, presenciamos panelas de pedra e ferro fundido sendo vendidas ao lado de panelas de vidro temperado e de aço inox, que apresentam como inovações tecnológicas promovidas ao longo dos anos.

Porém, apesar de tais contrastes, é sabido que cada material interfere de maneira diferenciada em contato com alimentos, e em muitos casos, pode influenciar no gosto do alimento preparado.

Quintaes (2000) afirma que:

"O saber popular há muito indicou que a utilização de panelas de ferro na cocção de alimentos é um meio preventivo e mesmo auxiliar no tratamento da anemia ferropriva, apontando diretamente para um possivel efeito migratório do ferro do utensílio para o alimento preparado. Por outro lado, podemos imaginar que o contrário também é verdadeiro: elementos indesejáveis contidos em determinados utensílios, como o alumínio e o níquel entre outros, podem migrar para os alimentos durante o processo de cocção."

\section{DESENVOLVIMENTO}

Foram estabelecidos critérios para a realização do trabalho, iniciado com o levantamento bibliográfico e pesquisa sobre o tema, aliados às pesquisas de concorrentes internacionais em mercado brasileiro. Posteriormente, foram realizados experimentos no laboratório de materiais cerâmicos da Universidade do Estado de 
Minas Gerais - Escola de Design, como forma de avaliar possíveis formulações de esmaltes que pudessem ser utilizados sobre superfícies de ferro fundido. Essas formulações pretendidas deveriam ser viáveis, o bastante para que pudessem ser replicadas em escala de manufatura, além de adequadas à realidade tecnológica das empresas situadas na região citada, tendo em vista o objetivo específico de promover a agregação de valor através dos atributos e propriedades, semânticos ou não, do revestimento cerâmico, tais como textura, cores, brilho e performance na utilização. Para isso, foram contatadas empresas de fundição, da cidade de Cláudio/MG, as quais pudessem fornecer amostras de panelas de ferro fundido para a realização dos experimentos.

As atuais práticas de esmaltação em metais são totalmente diferentes dos métodos precursores. Houve um direcionamento de pesquisas e desenvolvimentos nas décadas de 40, principalmente porque a indústria foi direcionada para produção em escala de peças de aço, voltadas à indústria de eletrodomésticos. No entanto, recentemente, mais uma vez a indústria voltou suas ações para a esmaltação através do processo úmido, aplicado em produtos de ferro fundido, como forma de agregar valor a estes produtos (DIAS \& GONTIJO, 2011; DIAS, 2009; DOORDAN, 2003; ELLIOT, 1983).

\subsection{Esmaltação em produtos de cocção}

A esmaltação consiste em um processo de revestimento que confere uma proteção contra corrosão de uma peça, neste caso utensílios de coç̧ão. O processo de esmaltação se baseia na fusão de fina camada de vidro sobre a superfície metálica que deve ser protegida. $O$ esmalte, por ser um vidro, apresenta uma superfície dura e lustrosa, resistente à corrosão, riscos e manchas. Daí o seu emprego no revestimento de utensílios domésticos, obras de arte etc. Deve-se salientar que o termo esmalte (mais corretamente, esmalte vítreo ou porcelanizado) possui um significado diferenciado do das tintas de acabamento brilhante (KOPPLIN, 1995).

Muitos produtos cerâmicos, como louça sanitária, louça de mesa, isoladores elétricos, materiais de revestimento e outros, recebem uma camada fina e contínua de um material denominado de esmalte ou vidrado, que após a queima adquire o aspecto vítreo. Esta camada vítrea contribui para os aspectos estéticos, higiênicos e melhoria de algumas propriedades mecânicas e elétricas (MÓL, 2005). O revestimento de esmaltação consiste de um aglomerado de $\mathrm{SiO} 2$, $\mathrm{TiO} 2$, sílica, titânio, alumina e óxidos de boro, sódio, potássio e cálcio (SHCHEPOCHKINA, 1995).

Pagliuca (2011) divide o revestimento cerâmico em três categorias: esmalte de cobertura terrosa, esmalte de cobertura branca e esmalte de cobertura colorida. Sendo que os esmaltes de cobertura terrosa possuem em sua composição a presença de argila; os esmaltes de cobertura branca apresentam em sua composição opacificantes, como por exemplo o óxido de estanho e, finalizando, os esmaltes de cobertura colorida recebem a adição de óxidos corantes, como o óxido de zinco, óxido de titânio ou óxido de ferro.

Conforme afirma ELLIOT (1983), a presença do elemento que permita a coloração do esmalte não interfere no composto, apenas no caso de a concentração ser elevada. Conforme o autor, em casos extremos, pode ser provocado manchas e até 
mesmo o desaparecimento da cor. Em sua análise, o autor afirma ser possível, coma adição de alguns elementos, a criação de tonalidades e efeitos que possam valorizar a superfície esmaltada. Assim, como exemplo, tem-se que a presença de óxido de chumbo em pequenas quantidades pode auxiliar no desenvolvimento de cores mais vivas; substâncias álcalis em teores elevados podem ser prejudiciais para a maioria dos corantes, dentre outros.

De maneira geral, a realização da esmaltação em aparelhos de confecção é realizada apenas no exterior da peça, em virtude que tais elementos de coloração podem contaminar os alimentos cozidos.

Assim, em boa parte das panelas analisadas, é realizado a esmaltação em tonalidade crème (bege) em seu interior, sem agente colorante específico ou material nocivo à saúde. MÓL (2005) afirma que grande problema com as panelas encontradas atualmente no mercado, a contaminação dos alimentos nelas preparados por metais pesados, tais como alumínio (Al), cádmio $(\mathrm{Cd})$, chumbo $(\mathrm{Pb})$, cobre $(\mathrm{Cu})$, cromo $(\mathrm{Cr})$, ferro (Fe), níquel (Ni) e zinco ( $\mathrm{Zn}$ ), entre outros, e materiais de revestimentos como o teflon e tintas e corantes utilizados em utensílios de cerâmica. O esmalte, dessa forma, funciona como agente protetor, na medida em que cria uma barreira entre o material esmaltado - no caso, o ferro fundido - e o alimento que está sendo preparado.

\subsection{Delimitações da esmaltação aplicada em ferro fundido}

As atuais práticas de esmaltação em metais são totalmente diferentes dos métodos precursores. Houve um direcionamento de pesquisas e desenvolvimentos nas décadas de 40 , principalmente porque a indústria foi direcionada para produção em escala de peças de aço, voltadas à indústria de eletrodomésticos. No entanto, recentemente, mais uma vez a indústria voltou suas ações para a esmaltação através do processo úmido, aplicado em produtos de ferro fundido, como forma de agregar valor a estes produtos (ELLIOT, Op.Cit.; DANIELSON, 1924)

A composição química do esmalte vítreo depende de sua utilização futura (HARRY, 2007). É importante, porém, que seu coeficiente de dilatação volumétrica (taxa de variação do volume por unidade de temperatura) seja compatível com o metal a ser esmaltado, caso contrário, o vidro se soltaria do metal em questão.

Um revestimento de base típico deve conter 39 a 42\% de tetraborato de sódio (também chamado de bórax $-\mathrm{Na}_{2} \mathrm{~B}_{4} \mathrm{O}_{7} \cdot \mathrm{H}_{2} \mathrm{O}$ ), 19 a $20 \%$ de Feldspato, 28 a $30 \%$ de $\mathrm{SiO}_{2}$ (sílica), 7 a $9 \%$ de carbonato de sódio $\left(\mathrm{Na}_{2} \mathrm{CO}_{3}\right)$ e pequena quantidade de outras substâncias, incluindo óxidos de cobalto (ou, por vezes, de molibdênio) para reforçar a aderência do esmalte ao metal. A camada seguinte de esmalte pode conter 23 a $26 \%$ de bórax, 13 a 15\% de feldspato, 33 a 36\% de sílica, 9 a 13\% de carbonato de sódio e outras substâncias, as quais garantem a cor e a fixação do esmalte (ADAMS, 2007).

A maior parte da esmaltação foi efetuada por via úmida. Uma espessa camada em suspensão de frita ${ }^{2}$ é aplicada por pulverização ou por mergulho, seguindo-se a secagem. A via seca é usada na esmaltação do ferro fundido, sendo úmida a primeira

\footnotetext{
${ }^{2}$ Suspensão de frita é o nome dado à mistura cerâmica contendo os componentes em suspensão líquida (água).
} 
"mão", enquanto as outras são aplicadas por aspersão do vidro moído sobre o objeto aquecido. Para um acabamento uniforme, necessitam-se vários ciclos de aspersão e aquecimento nos fornos intermitentes (muflas) ou, industrialmente, num forno em túnel (GAI, 2009; GARLAND, 1986).

Neste último caso, os objetos passam pelo forno lentamente, sobre uma esteira, num trajeto de 20 min., porém, só se detém na parte quente do forno durante 4 min. Os revestimentos de base são normalmente aquecidos a 800-850 C, ao passo que as "mãos" posteriores recebem aquecimento em tempo menos e temperatura levemente inferior. No processo de aquecimento, o vidro se derrete e distende sobre o metal.

Já quanto aos dados sobre o efeito dos constituintes do ferro fundido cinzento na sua capacidade de ser esmaltado são generalizadas. Para Mironenko, Naletov \& Paladich (1982), a qualidade de esmaltação depende não apenas da composição do esmalte, mas também sofre a influência da microestrutura, composição e propriedades do metal a ser esmaltado.

Para O’Byrne (2004), determinadas características físico-químicas do ferro fundido para esmaltação são fundamentais para o êxito nas peças revestidas. Metalurgicamente, o ferro fundido tem que ter uma variedade de elementos em intervalos relativamente estreitos para atender requisitos de processamento $\mathrm{e}$ aplicação. A composição química do ferro fundido para esmaltação, segundo este autor deve seguir a seguinte receita: Carbono de 3,2-3,6\% (sendo em forma de grafita de 2,8-3,2\% e carbono combinado de 0,2-0,5\%), Silício de 2,25-2,70\%; Manganês de 0,45-0,65\%; Fósforo de 0,30-1,00\% e Enxofre de 0,05\% a 0.10\%. Segundo o autor, cada um dos elementos descritos tem um importante papel na obtenção de um bom produto esmaltado. Todavia, sabe-se que a preparação prévia dos produtos para a esmaltação é fundamental para a qualidade do produto final.

\subsection{Realização dos ensaios}

Após a etapa da revisão da literatura, foram realizados experimentos no Laboratório de Materiais Cerâmicos da Universidade do Estado de Minas Gerais Escola de Design (Figura 4).

Para o desenvolvimento do revestimento cerâmico de artefatos de cocção de ferro fundido, foram utilizadas composições sem presença de chumbo (PAUKSH, 2012; PAGLIUCA, 2011), sendo que para revestimento de coloração branca foi adicionado $3 \%$ em peso de óxido de titânio e para revestimento marrom foi adicionado $7 \%$ em peso de óxido de ferro, em ambos os casos com adição de $50 \%$ em peso de água deionizada, obtendo densidade igual a $1,7 \mathrm{~g} / \mathrm{cm} 3$ (SEXTON \& STORIE, 2004).

Para o desenvolvimento do revestimento cerâmico de artefatos de cocção de ferro fundido, foram utilizadas composições sem presença de chumbo (PAGLIUCA, 2011), sendo que para revestimento de coloração branca foi adicionado $3 \%$ em peso de óxido de titânio e para revestimento marrom foi adicionado 7\% em peso de óxido de ferro, em ambos os casos com adição de $50 \%$ em peso de água deionizada, obtendo densidade igual a $1,7 \mathrm{~g} / \mathrm{cm} 3$. 

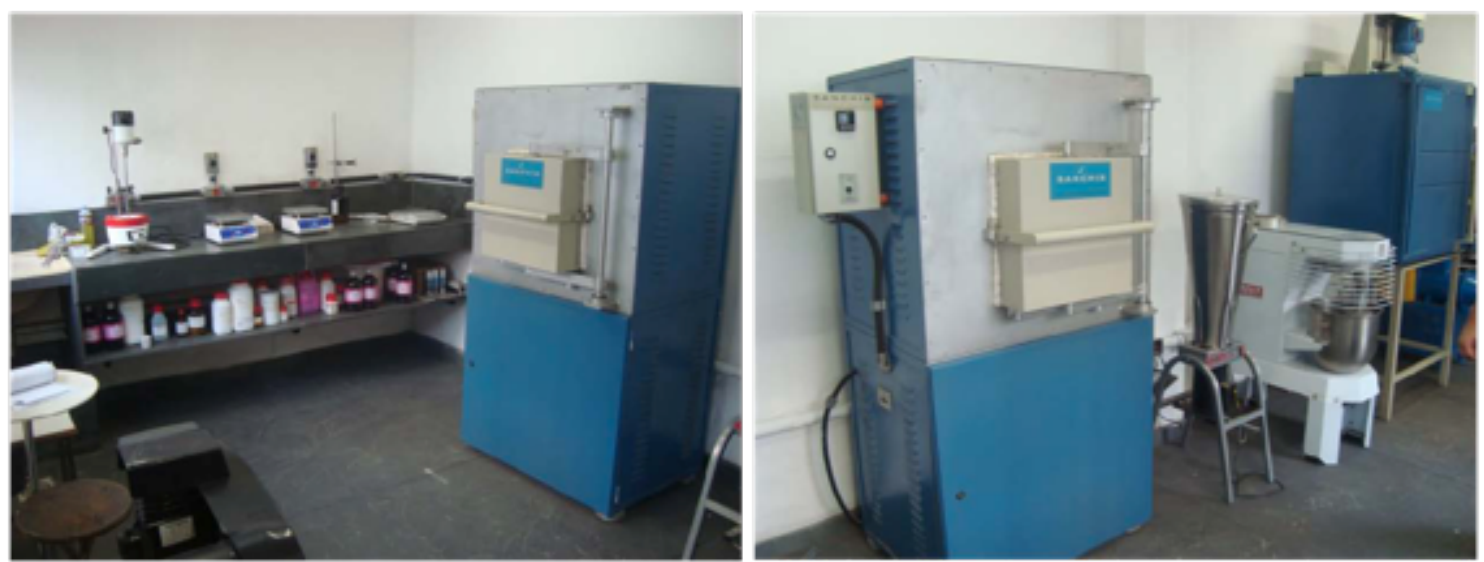

Figura 4 - Infraestrutura do Laboratório de Materiais Cerâmicos da Escola de Design/UEMG.

Fonte: Elaborado pelos autores, com base na pesquisa realizada.

\section{CONCLUSÃO}

Os estudos experimentais, até o presente momento, foram suficientes para avaliar resultado a partir da repetição e comparação dos ensaios executados de caracterização e comparação com os dados obtidos no levantamento bibliográfico inicial, especialmente em base das referências descritas por Pagliuca (2011).

A partir da definição dos parâmetros experimentais para a caracterização do material base, formulação do esmalte, forma de aplicação e parâmetros de queima, serão aplicados em amostras padronizadas (corpo de prova) no formato aproximado de $80 \times 80 \mathrm{~mm}$ de ferro fundido, fornecidos pelas empresas da região (Figura 5).

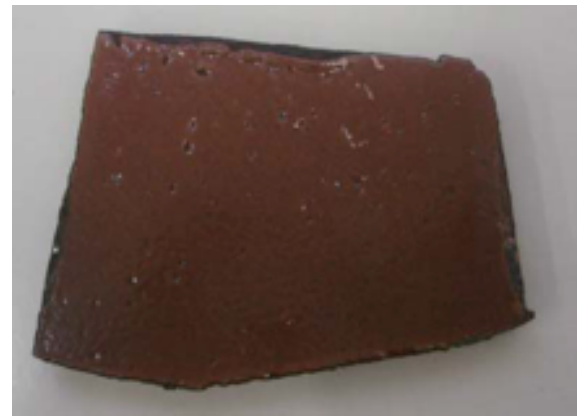

Figura 5 - Amostra esmaltada na composição desenvolvida no projeto. Cor marrom-avermelhada obtida através do pigmento óxido de ferro.

Fonte: Elaborado pelos autores, com base na pesquisa realizada.

Numa etapa posterior, a aplicação do esmalte será em produtos reais, panelas, fornecidas pelas mesmas empresas, para avaliar qualitativamente o perfil de distribuição térmica em artefato de cocção, após aplicação do revestimento desenvolvido, a partir de análise termográfica por infravermelho em simulação do uso.

A esmaltação de artefatos de cocção em ferro fundido apresenta elevada complexidade, ainda que seja possível verificar na literatura todas as etapas para a realização do processo, o sucesso depende de grande conjunto de fatores, dos quais foi possível obter resultados satisfatórios em cada situação de forma isolada.

O presente trabalho apontou as diretrizes para o desenvolvimento de revestimento cerâmico para artefatos de cocção em ferro fundido. No entanto, é 
necessário ressaltar que os resultados foram analisados de forma isolada, de acordo com cada parâmetro relevante ao processo, sendo assim se faz necessário à continuação do trabalho utilizando os dados desse trabalho de forma conjunta, a fim de obter um revestimento adequado para o setor.

\section{REFERÊNCIAS}

ADAMS, R. China supplies more and more of the world's inorganic pigment needs. Focus on Pigments, November 2007, Issue 11, p. 1-3, 2007.

DANIELSON, R. Wet-process enamels for cast iron. Journal of the Franklin Institute, March 1924: vol 197, Issue 3, p. 401-403, 1924.

DIAS, M. Regina Álvares Correia. Percepção dos materiais pelos usuários: modelo de avaliação Permatus. 1 v. Tese (Doutorado) - Universidade Federal de Santa Catarina, Centro Tecnológico, Programa de Pós-graduação em Engenharia e Gestão do Conhecimento, Florianópolis, 2009.

DIAS, R. A; GONTIJO, L. Método para a seleção de materiais centrado nos usuários. In: Design \& Método. Cadernos Avançados de Estudos em Design, EdUEMG, 2011.

DOORDAN, Dennis P. On Materials. Design Issues, n. 19, 2003, pp. 3-8.

ELLIOT, G. F. Current pactices in enamelling cast iron by the wet-process method. Proceedings of the Porcelain Enamel Institute Technical Forum, p 459-461, 1983.

GAl, Bruno de Freitas. Esmaltação inorgânica em lâminas de aço. 2009. 123 f. Monografia (Tecnólogo em Cerâmica) no curso de Tecnologia em Cerâmica da Universidade do Extremo Sul Catarinense,UNESC, Santa Catarina, 2009.

GARLAND, B. T. The designing of products utilizing the special properties of vitreous enamel. Materials \& Design, Volume 7, Issue 1, January-February 1986, Pages 44-48, 1986.

HARRY, F. State of the Art of the enamelling of cast iron grates. Ceramic Engineering and Science Proceedings, v 27, n 9, p 179-181, 2007, 68th Porcelain Enamel Institute Technical Forum.

KOPPLIN, Kara Joyce. Controlling product design, foundry practices, and enamel plant processes to improve cast iron and porcelain enamel compatibility. Ceramic Engineering and Science Proceedings, v. 16, n. 6, nov-dec 1995, pp. 49-56.

KRIPPENDORFF, Klaus. Design centrado no ser humano: uma necessidade cultural. Estudos em Design, Rio de Janeiro, v. 8, n. 3, set. 2000, p. 87-98.

LJUNGBERG, L. Materials selection and design for development of sustainable products. Materials \& Design 2007, vol 28, Issue 2, p. 466-479, 2007.

MIRONENKO, V.; NALETOV, A. \& PALADICH, V. Preparation of Iron Castings for Enamelling. Chemical and Petroleum Engineering, v 18, n 5-6, p 208-209, May-Jun 1982.

MOL, Alberto de Souza. Utilização de porcelanato em utensílios para cocção. 2005, 92 f. Dissertação (Mestrado em Engenharia de Materiais) - REDEMAT/UFOP, Ouro Preto, 2005. 
O'BYRNE, L. Cast iron quality for good porcelain enameled parts. Ceramic Engineering and Science Proceedings, v 25, n 5, p 109-111, 2004.

PAGLIUCA, Silvano. Porcelain (Vitreous) Enamels: and industrial enamelling processes, the preparation, application and properties of enamels. 3 Ed. Mantova: Tipografia Commerciale Srl, 2011.

PAUKSH, P. G. Some problems with enameling cost iron articles. UDC 666293.Disponível em <http://www.springerlink.com/content/g215hm7702v79070>. Acesso em nov. 2012.

QUINTAES, K.D. Utensílios para alimentos e nutrição. Revista Nutrição, Campinas, Vol13 n.3 151-156, set./dez., 2000 pg 151-156.

SEXTON, M. \& STORIE, O. Preparation of cast iron for porcelain enameling. Ceramic Engineering and Science Proceedings, v 25, n 5, p 137-139, 2004.

SHCHEPOCHKINA, Y. Enamel for cast iron. Steklo i Keramika, n 4, p 27, Apr 1995. Vol 5, Issue 4, December 1990, Pages 361-375, 2003. 